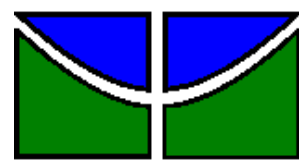

UNIVERSIDADE DE BRASÍLIA

Faculdade de Educação - UAB/UnB/ MEC/SECAD Curso de Especialização em Educação na Diversidade e

Cidadania, com Ênfase em EJA.

EDNA DE SOUSA RIBEIRO

ELIAS LEOCÁDIO

ROBERTO LIVIO

SÉRGIO DE JESUS DOS SANTOS

Evasão Escolar - Possíveis causas e ações alternativas para minimizar a evasão na Educação de Jovens e Adultos do 3은 Segmento do Centro Educacional 04 de Sobradinho II.

BRASÍLIA, DF

JULHO/2010 
UNIVERSIDADE DE BRASÍLIA

Faculdade de Educação - UAB/UnB/ MEC/SECAD

Curso de Especialização em Educação na Diversidade e

Cidadania, com Ênfase em EJA

\title{
Evasão Escolar - Possíveis causas e ações alternativas para minimizar a evasão na Educação de Jovens e Adultos do 3을 Segmento do Centro Educacional 04 de Sobradinho II.
}

\author{
EDNA DE SOUSA RIBEIRO \\ ELIAS LEOCÀDIO \\ ROBERTO LIVIO \\ SÉRGIO DE JESUS DOS SANTOS
}

Ruth Gonçalves de Farias Lopes

Cléssia Mara Santos

PROJETO DE INTERVENÇÂO LOCAL

BRASÍLIA, DF Julho/2010 
Sousa, Edna. Leocádio, Elias. Livio, Roberto. Jesus, Sérgio.

Evasão escolar - Possíveis causas e ações alternativas para minimizar a evasão no $3^{\circ}$ segmento - $1^{\text {a }}$ etapa da EJA - CED. 04 de Sobradinho II.

Brasília, 2010.

$26 \mathrm{p}$.

Projeto de Intervenção Local. Faculdade de Ciências da Educação. Universidade de Brasília, Brasília.

1.Evasão escolar na EJA - 3ํㅗㄴ segmento - 1aㅡ etapa. 
UNIVERSIDADE DE BRASÍLIA

Faculdade de Educação - UAB/UnB/ MEC/SECAD

Curso de Especialização em Educação na Diversidade e

Cidadania, com Ênfase em EJA.

EDNA DE SOUSA RIBEIRO

ELIAS LEOCÁDIO

ROBERTO LIVIO

SÉRGIO DE JESUS DOS SANTOS

\section{Evasão Escolar - Possíveis causas e ações alternativas para minimizar a evasão na Educação de Jovens e Adultos do $3^{\circ}$ Segmento do Centro Educacional 04 de Sobradinho II.}

Trabalho de conclusão do Curso de Especialização em Educação na Diversidade e Cidadania, com Ênfase em EJA, como parte dos requisitos necessários para obtenção do grau de Especialista na Educação de Jovens e Adultos.

\begin{tabular}{c}
\hline $\begin{array}{c}\text { Ruth Gonçalves de Farias Lopes } \\
\text { Professor Orientador }\end{array}$ \\
\hline Cléssia Mara Santos \\
Tutor Orientador \\
\hline Vânia Maria do Rego Silva Costa \\
Avaliador Externo
\end{tabular}

BRASÍLIA, DF Julho/2010 


\section{AGRADECIMENTOS}

Agradecemos a Deus, em primeiro lugar, que no corre-corre de nossa vida diária, esquecemos tantas vezes de enaltecer pela oportunidade de trabalhar com a EJA e aprender todos os dias com nossos alunos, que nos concedem sempre a serenidade necessária para aceitar as coisas que não podemos modificar e coragem para modificar aquelas que podemos.

Também agradecemos a nossa orientadora, Prof ${ }^{a}$. Ruth Gonçalves de Farias Lopes e a nossa tutora orientadora, Prof ${ }^{a}$. Cléssia Mara Santos, por todo empenho, dedicação, paciência, incentivo e companheirismo apresentados desde a aula inaugural do curso, durante o decorrer do mesmo e ao término do trabalho final de conclusão, não deixando-nos desistir jamais.

Por fim, aos nossos familiares e amigos, pela tolerância, paciência e compreensão pelas longas horas em que efetivamente estávamos destinando ao nosso projeto final, acreditando sempre no profissional de valor capaz de transformar o mundo e as pessoas em melhores seres humanos! 


\section{RESUMO}

O Projeto de Intervenção Local - PIL, objetiva desenvolver uma proposta de intervenção que contribua para solucionar problemas relacionados à evasão escolar no âmbito do $3^{\circ}$ segmento - 1aㅡ etapa da Educação de Jovens e Adultos do Centro Educacional 04 de Sobradinho II, através de um trabalho interdisciplinar envolvendo professores, alunos, servidores e comunidade, na construção e utilização de estratégias que permitam um maior envolvimento e convivência social entre todos os sujeitos da educação presentes no referido ambiente, minimizando assim, 0 abandono desenfreado aos estudos, enfrentado pelos alunos da EJA. Este projeto foi idealizado como respostas às questões relacionadas aos problemas de alto índice de evasão escolar observado em escolas da rede pública do D.F e especialmente no CED.04 de Sobradinho II, nosso foco de investigação. Em suma, o projeto viabiliza alternativas para permanência dos alunos na escola, evitando assim, a saída em massa da classe discente de EJA, por motivos diversos e muitas vezes alheios a sua própria vontade, resultando em oferecer solução a um comportamento centrado na permanência e na convivência harmoniosa do aluno rumo ao ensino prazeroso, como fonte de mudança nos paradigmas de sua vida, oferecendo meios para transformar a realidade em que vive.

Palavras-chaves: intervenção, evasão escolar, permanência, convivência social. 


\section{SUMÁRIO}

1.0 Dados de Identificação dos Proponentes ....................................................... 08

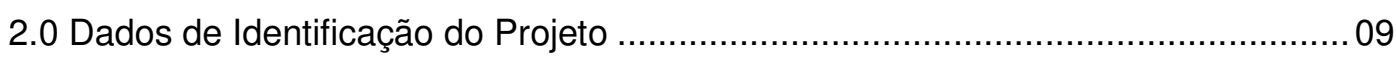

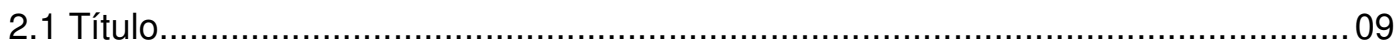

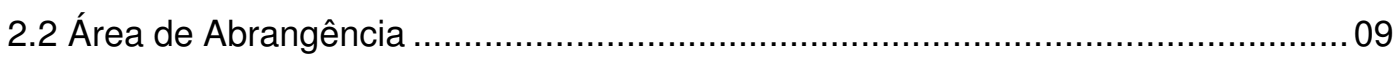

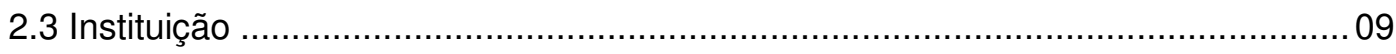

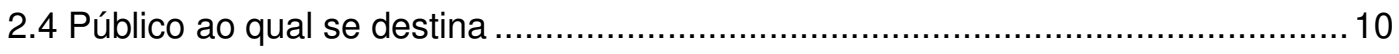

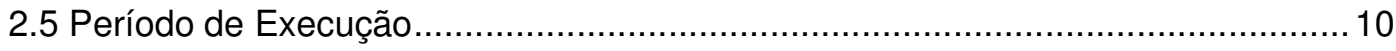

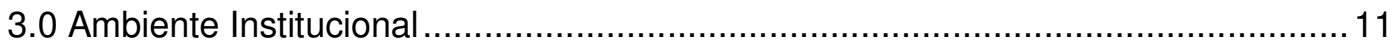

4.0 Justificativa e Caracterização do Problema................................................... 15

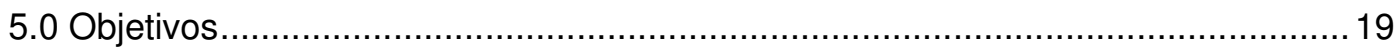

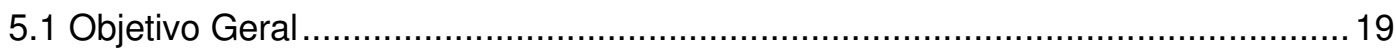

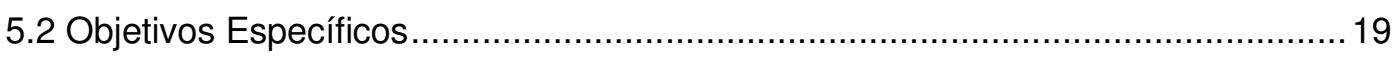

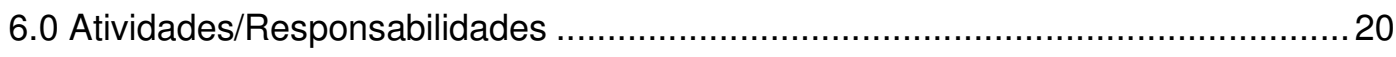

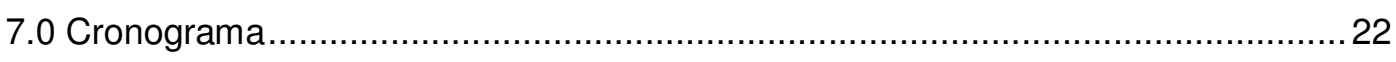

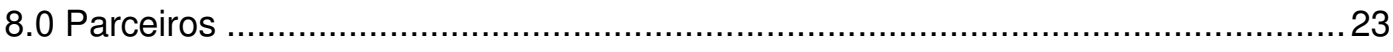

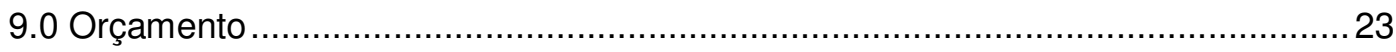

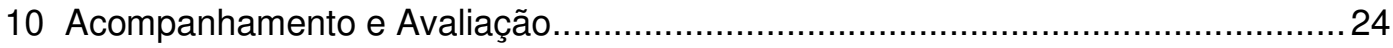

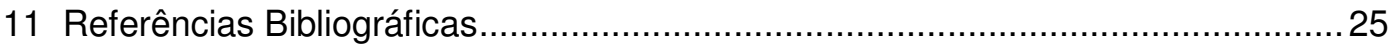




\section{UNIVERSIDADE DE BRASÍLIA \\ FACULDADE DE EDUCAÇÃO \\ UAB/ UNB.}

Curso de Especialização em Educação na Diversidade e Cidadania, com Ênfase em

EJA.

Parceria MEC/SECAD.

\section{I - Dados de Identificação dos Proponentes.}

1. Este projeto propõe minimizar o elevado índice de evasão escolar dos alunos do terceiro segmento de Educação de Jovens e Adultos (EJA), da rede oficial da Secretaria de Estado de Educação do Distrito Federal, com destaque para o Centro Educacional 04 de Sobradinho II.

1.1 - Integrantes do Grupo:

Elias Leocádio da Silva

Sérgio de Jesus dos Santos

Edna de Sousa Ribeiro

Roberto Lívio.

1.2 - Turma " G " - Curso de Especialização em Educação Diversidade e Cidadania com ênfase em EJA.

1.3 -Telefones para contatos: 61- 34853918/9182-9190 Elias Leocádio.

85002060/9155-8312 Edna Sousa.

85618010/9163-8589 Roberto Lívio.

84483903/ 3387-6483 Sérgio Jesus.
e-mails: elias.leocadio@uol.com.br
Elias Leocádio.
ednasous2005@yahoo.com.br
Edna Sousa.
robertolivio2005@hotmail.com
Roberto Lívio.
sersantjes@yahoo.com.br
Sérgio Jesus. 
2. Identificação do Projeto: Projeto Pedagógico de Intervenção Local (PIL).

2.1-Título - Evasão Escolar: Possíveis causas e ações alternativas para minimizar a evasão no $3^{\circ}$ segmento da EJA, $1^{1}$ etapa, do Centro Educacional 04 de Sobradinho II, DF.

2.2- Abrangência de Ação - Local: Centro Educacional 04 de Sobradinho II. Porém, dada a natureza do PIL, poderá ser aplicado em outras escolas da Rede Pública da SEEDF, pois o seu objetivo fim é reduzir a gravidade do problema da evasão, tornar os alunos mais freqüentes e menos dispendiosos para o erário público.

Todos os estudantes têm potencialidades para fazer muito pela melhoria de suas próprias vidas. "Nada é feito com as mãos sem que não venha do pensamento." (FREIRE, 1.996).Então,ensinar o estudante à pensar é ensinar-Ihe a viver melhor.

Em qualquer escola, em qualquer espaço das atividades humanas, é possível promover mudanças. A aplicação de um projeto como PIL, poderá ser executado em qualquer esfera da Rede Oficial de Ensino. "A Educação é uma participação comunitária com perspectivas progressistas."(FREIRE,1.996).Cabe-nos estimular e facilitar a prática educativa.

2.3- Identificação da Instituição de Ensino.

Nome: Centro Educacional 04 de Sobradinho II.

Endereço: AR 10, Conjunto 09, Área Especial № 01.

Bairro: Setor Oeste de Sobradinho.

Cidade: Sobradinho II

Estado: DF.

CEP: 73062-109.

Telefone: (61) 3901-7962.

FAX: (61) 3901-7963.

E-mail: ced04sobradinho@gmail.com

Localização/Zona: Urbana.

Portaria de autorização/credenciamento: Portaria 03 de 12/01/2004 - SEDF.

Número da Escola (Censo Escolar): 53012542.

DIRETOR E VICE-DIRETOR (A) DA ESCOLA

Nome: Wagner Macário de Carvalho - Matrícula Funcional - 44.169-4

Telefone: (61) 3387-4427

FAX: (61) 3901-7963

E-mail: wagner.macario@gmail.com 
Nome: Maria da Paz Bezerra Paes Leme - Matrícula Funcional - 58.666-8

Telefone: (61) 3387-8507

E-mail: casapaesleme@gmail.com

2.4 - Público alvo a ser contemplado com o projeto proposto:

Terceiro segmento, etapa I, II e III, turno em que as turmas estiverem inseridas.

2.5 - Previsão do início da aplicação do projeto proposto:

Segundo semestre de 2010, do reinício do semestre ao final do ano letivo de 2010. Agosto de 2.010 à Dezembro de 2.010. 


\section{0 - Ambiente institucional, local onde se situa o problema diagnóstico:}

O Centro Educacional 04 Sobradinho II, local da identificação do problema, que deu origem ao presente projeto de intervenção local, se propõe a intervir numa dimensão complexa por se tratar de uma questão de natureza político-pedagógica com riqueza de complexidade num universo institucional. Na escola, em geral, e principalmente na Educação de Jovens e Adultos, é comum a evasão escolar de alunos, em particular das escolas públicas com destaque para o 3 o segmento da EJA, do Centro Educacional 04 de Sobradinho, para o qual sugerimos procedimentos intervencionistas, para solução da problemática da Evasão Escolar. Tais sugestões podem ser de ordem docente, como por exemplo na mudança de postura do professor perante a turma de EJA, como também por parte da escola, ou seja, mudanças administrativas, como na organização de alunos com níveis de pré requisitos semelhantes, em determinada série.

O projeto de intervenção local ora proposto busca solucionar um problema de natureza pedagógica, que prevê medidas didático-pedagógicas e técnicas administrativas apropriadas, que no curso da administração de ações bem orientadas, compartilhadas por todo o corpo docente e a direção da escola, possamos promover a execução do projeto com êxito.

Para que alcancemos as questões previamente delineadas no diagnóstico e que possamos buscar a solução para o problema do alto índice de Evasão Escolar na EJA, no contexto das escolas do D.F, e também no Centro Educacional 04 de Sobradinho II, de modo geral, que prejudica o sucesso do nosso trabalho e a educação como um todo, temos que nortear um caminho a ser seguido, ou seja, um eixo orientador de metas de promoção e permanência do aluno na escola.

As soluções dos problemas vêm das intenções que emanam do agente público, que deseja mudanças de uma realidade existente no campo em que atua em defesa do sucesso dos alunos.

Qualquer projeto com fins sociais surge de necessidades coletivas, e a nossa proposta tem a finalidade de suprir carências, advindas muitas vezes de ordem sóciocultural, político-econômicas, do ambiente social, inerente aos estudantes mencionados. As circunstâncias os levam a atitudes que muitas vezes vão de encontro a sua própria vontade, como o abandono escolar.

Para entender melhor a história de nossa Instituição Escolar, eis aqui uma breve abordagem histórica:

O ato da criação do Centro Educacional 04, surgiu da reivindicação da comunidade no ano de 1998, junto à Comissão responsável pelo orçamento participativo destinado à 
localidade de Sobradinho II. A comunidade local sentia a necessidade urgente da criação de um Centro Educacional que atendesse aos jovens estudantes ali residentes, evitando que se deslocassem para estudar em Sobradinho I.

A concretização das instalações do Centro Educacional 04, só se deu no dia 30 de novembro de 1998, na AR 10 Conjunto 09 - Área Especial 01. Sua funcionalidade total só foi possível a partir do dia 03 de março de 1999. O corpo administrativo foi formado pelos professores Edilson Pacheco da Rocha, como Diretor e Mauro Farias Medeiros, como ViceDiretor. O total de jovens atendidos naquele ano foi de aproximadamente 1.393, distribuídos nos 3 turnos, nas turmas de $5^{\mathrm{a}}$ a $8^{\mathrm{a}}$ séries do Ensino Fundamental e do $1^{\circ}$ ano do Ensino Médio.

Mesmo sendo uma escola nova, o Centro Educacional 04, desde seu primeiro ano de funcionamento vem se destacando por desenvolver projetos, tendo como pressuposto básico, para a garantia da qualidade e consistência de suas atividades, a participação coletiva dos servidores e comunidade escolar.

A Escola sofreu, em seus dez anos de funcionamento, com a rotatividade de professores e do corpo administrativo, mesmo assim já foi premiada com alguns projetos.

Em 2001, foi premiada com "O Projeto Sacudindo a Poeira dos Saberes de Cá" que teve como objetivo o resgate histórico-cultural de Sobradinho II, registrando o histórico da cidade através da metodologia da pesquisa oral. Foi coordenado pela professora Vera Lúcia Soares Souza, com a participação de alunos do noturno e comunidade local.

Em 2005, foi a vez do "Projeto Direitos Humanos uma Lição de Cidadania", onde apresentamos aos alunos e comunidade a importância do conhecimento e respeito aos direitos humanos como pilar fundamental da construção da cidadania, tendo a participação de professores e alunos dos três turnos.

Em 2006, a instituição recebeu menção honrosa pela participação no Prêmio de Gestão e se destacou pela média alcançada na Prova Brasil, realizada no ano de 2005.

Em 2008, recebeu o Prêmio Atitude Senna da Fundação Athos Bulcão, pelo "Projeto Fazendo Arte, Colorindo a Vida", coordenado pela professora Rosângela Cândido Peixoto e contou com a participação dos alunos do Ensino Médio do turno matutino.

O Centro Educacional 04 tem como missão, o esforço conjunto para que o aluno tenha a possibilidade de realizar seus objetivos individuais, mas sempre associando a necessidade de se voltar, também, para a vida coletiva, percebendo a importância dos valores éticos e morais que ressaltam o viver em comunidade e para a comunidade.

Neste ano letivo, a Escola continua sob a direção do professor Wagner Macárío de Carvalho e da professora Maria da Paz Bezerra Paes Leme, após realização de referendo da comunidade escolar, em 2009. Conta com um corpo docente e administrativo 
comprometido com a causa da educação e determinado em fazer valer o Manifesto 2000, lançado pela UNESCO em março de 1999, por uma "Cultura de Paz e Não-Violência", como garantia ao respeito a todas as formas de vida, que todos os seres humanos saibam compartilhar, ouvir para compreender, preservar o planeta e redescobrir a solidariedade.

Encontram-se neste ano letivo de 2010, matriculados aproximadamente 1.966 alunos nos três turnos, atendendo $8^{\mathrm{a}}$ séries, do Ensino Fundamental/Regular; $5^{\underline{a}}$, $7^{\mathrm{a}}$ e $8^{\mathrm{a}}$ do Ensino Fundamental/EJA; $1^{\circ}, 2^{\circ}$ e $3^{\circ}$ anos do Ensino Médio, nas modalidades regular e EJA, e Programa Vereda (Correção de Fluxo). Atende Classes de Ensino Especial e disponibiliza espaço para atendimento em Salas de Recurso.

Visando a melhoria na qualidade e no desempenho da Escola, desde 2008, a escola está inserida no Programa PDE Escola e Mais Educação e, em 2010, no Programa Ensino Médio Inovador. Todas as ações desenvolvidas por tais programas, sua assistencia técnica e recursos financeiros estão voltados para a garantia da melhoria da aprendizagem efetiva dos alunos na Escola.

Essa instituição, com o apoio da Diretoria Regional de Ensino de Sobradinho, vem desenvolvendo um trabalho relevante, de natureza eminentemente sócio-pedagógica, oferecendo à comunidade o perfil de uma escola de referência.

A "Escola Aberta à Comunidade" é um projeto de escola interativa, em tempo integral, sendo um programa governamental ao qual a escola aderiu. Disponibiliza oficinas educativas às crianças e jovens do ensino regular, possibilitando realização de sonhos de muitos jovens e adultos da comunidade de Sobradinho II com poucas condições sócioeconômicas, e que, por ausência de uma política pública destinada à minimização do estado de pobreza, a escola oportuniza-os o acesso aos meios culturais e tecnológicos. Em nossa escola, este projeto funciona aos fins de semana em parceria com o governo federal.

O Programa Escola Aberta é um Programa Estadual, onde seu objetivo é contribuir para a melhoria da qualidade da educação, à inclusão social e à construção de uma cultura de paz, mediante ampliação de atividades oferecidas à comunidade.

As unidades de ensino que desenvolvem o "Escola Aberta" devem organizar as atividades a partir de demandas da comunidade, que apropriarão o espaço público escolar, no nosso caso o Centro Educacional 04, em conformidade com a proposta pedagógica do programa. As atividades podem ser alternativas nas áreas de Educação, Esporte/Lazer e Recreação, Cultura e Arte, qualificação para o trabalho e geração de renda.

A equipe do programa é integrada por um coordenador escolar e um professor comunitário, onde a responsabilidade pela composição da equipe é do Conselho Deliberativo da Comunidade Escolar de cada escola. Conforme o projeto, a equipe é responsável pela abertura da escola nos finais de semana. A seleção de "oficineiros" 
(responsáveis pelas oficinas), desenvolvem uma concepção de gestão compartilhada, coresponsabilizando 0 conjunto dos sujeitos que estão envolvidos no processo de desenvolvimento das atividades.

Essas oficinas serão desenvolvidas por meio de voluntariado, entendendo-se como tal, "atividade não remunerada, prestada por pessoa física à entidade pública de qualquer natureza, ou à instituição privada de fins não lucrativos, que tenha objetivos cívicos, culturais, educacionais, científicos, recreativos, ou de assistência social."

A prestação de contas do programa Escola Aberta seguirá os mesmos procedimentos e prazos definidos para os recursos do Plano de Desenvolvimento da Escola (PDE).

A escola,por tudo acima mencionado, abre oportunidade para todos aqueles que não puderam continuar e/ou reiniciar seus estudos, sendo que muitos deles não chegaram a iniciar os estudos. Assim, está sendo posto em prática, apesar da escassez de recursos financeiros oriundos do poder público nessa instituição, a oportunidade para todos que desejam estudar, nos três turnos disponíveis: matutino, vespertino e noturno.

O Centro Educacional 04 de Sobradinho II está vencendo desafios, superando obstáculos, desenvolvendo trabalhos sócio-educativos e culturais, inibindo desvios de conduta comportamentais, a exemplo do fenômeno bullyng- fenômeno social muito conhecido também pelas famílias de baixa renda das periferias do DF. 


\section{Justificativa e caracterização do problema.}

A evasão escolar, segundo o Dicionário Aurélio da Língua Portuguesa é considerado o mesmo que deserção escolar, considerando o fenômeno que expressa o número de educandos de um grau de ensino ou de uma série escolar, que abandonam definitiva ou temporariamente a escola.

Educandos que, por razões financeiras de inadaptação, entre outras, não completaram um determinado período de formação.

A evasão escolar ocorre por motivos geralmente atribuídos às dificuldades financeiras, ao ingresso prematuro no mercado de trabalho, à troca de domicílio, à doença, à falta de interesse do aluno ou de seus responsáveis, às dificuldades de acesso à escola, aos problemas domésticos, à separação dos pais ou à reprovação do aluno.

A evasão é caracterizada como uma expulsão escolar, porque a saída do aluno da escola não é um ato voluntário, mas uma imposição sofrida pelo estudante, em razão de condições adversas e hostis do meio.

A grande maioria dos estudantes evadidos deixa a escola no segundo semestre , ou até ao término do primeiro semestre, por considerar -se incapaz de passar de ano.

Assim sendo, evasão escolar é o fenômeno em que um ou mais alunos abandonam a escola durante o ano letivo, por motivos de desinteresse, por falta de estímulo, por se considerarem incapaz de passar de ano, ou por motivos sócio-econômicos.

Executar um plano político-pedagógico, voltado exclusivamente para manter os alunos efetivamente na escola, acionando todos os mecanismos de que a escola dispõe para conter esse fenômeno reclamado pela instituição educativa para que possamos trabalhar com uma quantidade de alunos compatível com a previsão do planejamento semestral ou anual, de uma forma mais satisfatória e racional.

Com orientações viáveis para intervenção local, intervindo com práticas pedagógicas educativas, promovendo incentivos, tornando mais flexíveis as exigências de horários de chegada, por se tratar de alunos trabalhadores, mães que cuidam de filhos no lar e outras atividades domésticas em geral.

Mesmo assim, os alunos devem ser entusiasmados e estimulados a manterem sua auto-estima, e mesmo enfrentando dificuldades adversas, serem motivados a jamais abandonarem seus objetivos, conforme preconiza o artigo $3^{\circ}$ da Lei de Diretrizes e Bases da Educação Nacional, à cerca da igualdade de acesso e permanência do aluno na escola.

Ao adotar certas práticas possíveis, como a postura do professor, a promoção da interdisciplinaridade entre os conteúdos e disciplinas, talvez consigamos a redução do índice de evasão do terceiro segmento da EJA, particularmente no Centro Educacional 04 de Sobradinho II, DF, nosso alvo de intervenção. 
Não podemos nos sentir confortáveis num contexto de interesse público relevante, como é o caso da Educação de Jovens e Adultos, implantada na Rede Oficial de Ensino, pela Secretaria de Estado e Educação do DF, convivendo com elevado índice de Evasão Escolar.

Segundo dados da própria SEEDF, os indicadores de evasão escolar , baseados nos dados da Pesquisa Nacional por Amostra de Domicílios- 2007, constatou-se que 1,9 milhões de adolescentes de 15 a 17 anos não estudavam. È praticamente o mesmo contingente de 2002 . Esse indicador comprovou que $30 \%$ dos jovens trabalham, mostrando que é preciso discutir formas de manter o jovem na escola com alguma ajuda financeira. $O$ trabalho de 15 a 17 anos é de baixa remuneração. Esse jovem está deixando de estudar e melhorar a sua inserção no mercado de trabalho no futuro.

Os dados ainda indicam que, de cada 60.000 matrículas efetuadas por ano no Distrito Federal em escolas públicas nas classes de jovens e adultos, 20.000 alunos não concluem o ano letivo.

Há que se tomar medidas político- pedagógicas, com o objetivo de solucionar questões relacionadas a qualidade do ensino -aprendizagem e a melhora do aproveitamento das potencialidades de jovens e adultos, no processo educativo, através do combate às causas da evasão escolar da EJA, como objetivo fim do nosso trabalho.

$\mathrm{Na}$ leitura de Paulo Freire, baseado no livro Pedagogia da Autonomia, o autor apresenta propostas de práticas pedagógicas necessárias à educação como forma de construir a autonomia dos educandos, valorizando e respeitando sua cultura e seu acervo de conhecimentos empíricos junto à sua individualidade.

A obra reúne experiências e novos métodos, que valorizam a curiosidade dos educandos e educadores, condenando a rigidez ética que se volta aos interesses capitalistas, que deixam à margem do processo de socialização os menos favorecidos.

Como eixo norteador de sua prática pedagógica, Freire defende que "formar" é muito mais que formar o ser humano em suas destrezas, atentando para a necessidade de formação ética dos educadores, conscientizando-os sobre a importância de estimular os educandos a uma reflexão crítica da realidade em que está inserido.

Ele ainda enfatiza alguns aspectos primordiais, porém nem sempre adotados pela sociedade atual, como: simplicidade, humanismo, ética e esperança, já que, na sua visão, o capitalismo leva a sociedade a um consumismo exacerbado e a uma alienação coletiva, através, principalmente, dos veículos de comunicação de massa.

Segundo o autor, o fracasso educacional deve-se em particular a técnicas de ensino ultrapassadas e sem conexão com o contexto social e econômico do aluno, mantendo-se 
assim o status quo, pois a escola ainda é um dos mais importantes aparelhos ideológicos do Estado.

Nesta visão, nosso projeto de intervenção local tenta minimizar a problemática de evasão escolar.

O presente projeto contempla interesse público também, o que contribui para a promoção social, o combate à desigualdade social na comunidade onde está inserida a clientela da base do curso de Educação de Jovens e Adultos, EJA. Estamos instituindo uma seara política de valorização à diversidade e cidadania.

Conforme mencionamos, o projeto visa minimizar o problema da evasão escolar, utilizando-se de técnicas pedagógicas aplicadas de conformidade com o projeto político pedagógico em curso da escola.

Um expediente desta importância, que tem fins multidimensionais, em que cada atitude tomada com objetivo social local, corresponde ao primeiro passo de uma caminhada quilométrica.

As ações conjuntas são decisivas no progresso de toda a sociedade. O que fizermos pelo progresso do nosso aluno, certamente beneficiará toda a sociedade.

Com medidas sócio-educativas que vão ao encontro das aspirações sociais, no caso do nosso principal objetivo, que é manter os alunos efetivamente na escola, até o término de cada etapa de estudo, dentro de cada segmento onde quer que eles estejam matriculados.

Cada conquista que contemplarmos no campo da educação, certamente estaremos defendendo a causa da promoção social e sócio-educacional para uma comunidade local ou regional, pois se trata de um segmento regional do Brasil.

O esforço que empreende-se no combate a evasão escolar, automaticamente, evitará desperdícios financeiros nos custeios com as escolas públicas e com a educação em geral.

A regência de uma classe se faz com programas e planejamentos integrados, desenvolvendo tarefas pedagógicas em salas de aula repletas de alunos, que é muito mais compensador e menos onerosa em custos financeiros que nas mesmas condições, numa sala de aula meio vazia. A evasão escolar é uma circunstância que nos preocupa enquanto educador, e decepciona a escola como instituição de ensino, em todos os aspectos funcionais. Uma das medidas seria ampliar em grande escala a quantidade de jovens e adultos beneficiados pelos Programas de Alfabetização e Educação para Jovens e Adultos, como política pública implantada pelo Ministério da Educação e Cultura, constituindo uma forma de resgatar o déficit dessa modalidade de educação no Brasil.

O desafio é o combate à desigualdade social, na diversidade da população brasileira Isso só será possível quando se conseguir uma forma de atrair jovens e adultos a 
iniciar e terminar os ciclos da escolarização de cada um, de forma ininterrupta e sem o fantasma da evasão escolar.

Na visão do filósofo Edgar Morin, o processo de ensino - aprendizagem, são eixos e, ao mesmo tempo, caminhos que se abrem a todos os que pensam e fazem educação e que estão preocupados com o futuro das crianças e adolescentes.

Sua leitura leva-nos à revisão das práticas pedagógicas da atualidade, tendo em vista a necessidade de situar a importância da educação na totalidade dos desafios e incertezas dos tempos atuais, onde os educandos devem trilhar um caminho mais acessível, na busca de um futuro mais humano, solidário e marcado pela construção do conhecimento. 


\section{Objetivos:}

\subsection{Objetivo Geral:}

Identificar possíveis causas da evasão escolar e operar alternativas para minimizá-las.

\subsection{Objetivos Específicos:}

5.1 - Realizar um levantamento junto aos alunos da $1^{\text {a }}$ etapa do $3^{\circ}$ segmento de EJA, no intuito da identificação das possíveis causas de evasão;

5.2 - Propor ações alternativas para minimizar a evasão na EJA, do Centro Educacional 04 de Sobradinho II, com base no diagnóstico realizado;

5.3 - Executar o projeto, pondo em prática as possibilidades viáveis dos meios disponíveis para a execução das estratégias planejadas, visando estancar as causas da evasão escolar;

5.4 - Oferecer flexibilização da assiduidade para aqueles alunos trabalhadores que não dispõem de tempo pleno, para freqüentar a todos os horários oferecidos;

5.5 -Disponibilizar material didático adequado a essa modalidade de ensino, quer seja: livros e cadernos de atividades, facilitando os trabalhos didáticos desenvolvidos em sala de aula;

5.6 -Utilizar a interação social bastante favorável aos alunos, tornar a escola um ambiente acolhedor e descontraído, porém respeitoso, sem comprometer a disciplina e os trabalhos didático-educativos;

5.7 - Empenhar atenção aos problemas de ordem pedagógico-social enfrentados por cada aluno, ajudando-o na superação de suas dificuldades no transcurso de seu aprendizado;

5.8 - Facilitar acesso a todos os meios didático-pedagógicos para motivar os alunos a terminarem o seu ciclo de estudo na escola;

5.9 -Oportunizar espaço didático-pedagógico para reforçar as defasagens de aprendizados em etapas de estudos anteriores, para que o aluno não perca a auto-estima e conclua seus estudos, além de acompanhar satisfatoriamente as atividades propostas. 


\section{Atividade/ Responsabilidade:}

Desenvolvimento dos procedimentos das atividades da pesquisa:

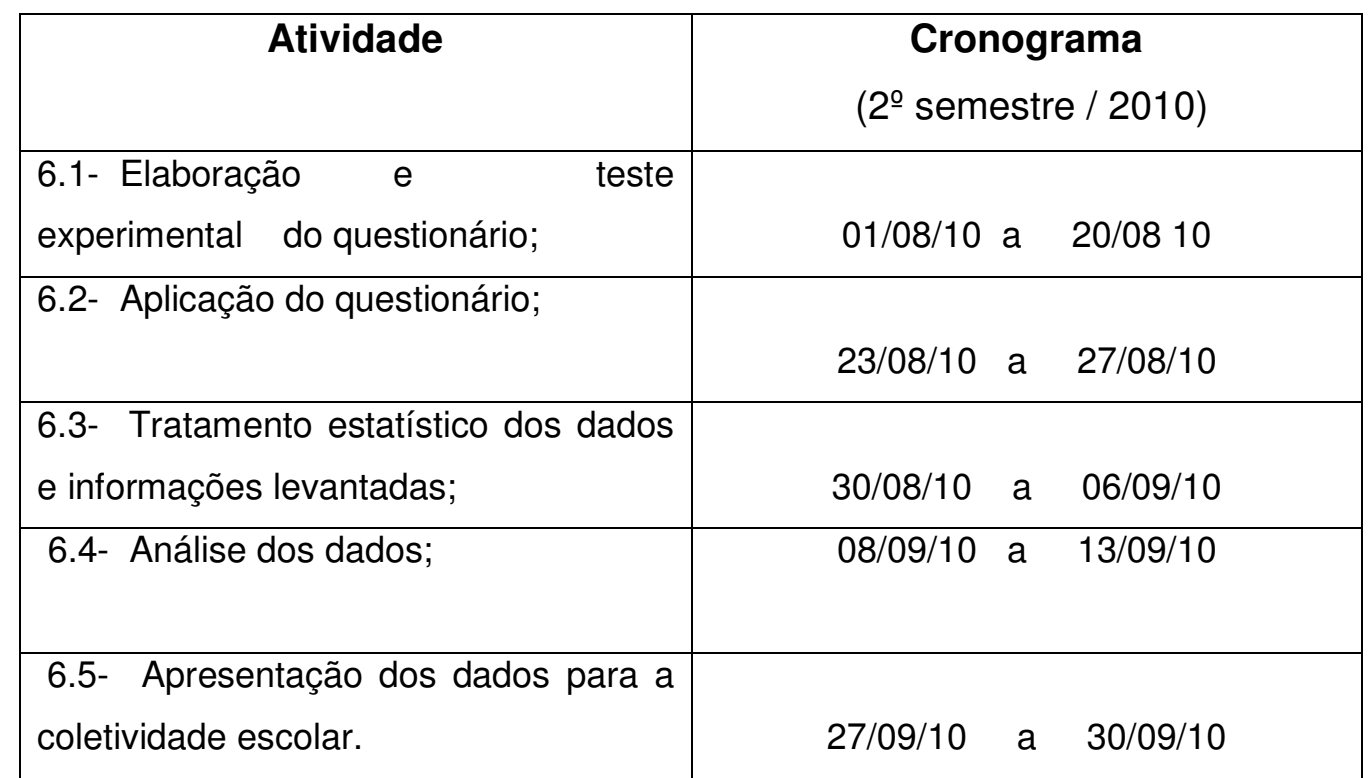

Para melhor entendimento das ações realizadas, explicaremos a seguir:

6.1 - Realização de encontros com integrantes da escola: alunos, professores, direção, servidores e representantes da comunidade, com tempo e espaço organizados pela escola, para juntos pensar em possíveis ações atenuadoras da evasão escolar na EJA.

6.2 - Elaboração de propostas, sintetizando as proposições dos diversos segmentos. 6.3 - Divulgação e discussão da proposta inicial com a comunidade escolar.

6.4 - Articulação junto ao conselho escolar e a direção da Instituição Educacional, para a inclusão do PIL no Projeto Político Pedagógico da escola.

6.5 - Pesquisa e levantamento dos dados informados e instrumentalização das ações administrativo-pedagógicas, com vistas ao cumprimento dos objetivos.

Um projeto terá que ser factível e suscetível de aplicação no campo de atividades no que foi elaborado, sendo que no transcurso da sua aplicação passará por coordenação e gerenciamentos dos agentes que o executará durante a sua aplicação.

Considerando a complexidade de um trabalho de natureza político-pedagógico, que envolve interferência em um processo para promover mudanças de realidades do sistema funcional, buscando-se corrigir deficiências num universo que envolve o ser humano, no 
caso numa escola pública ou particular, todo um conjunto do sistema será mobilizado para se promoverem as mudanças propostas no projeto.

Há de existir alguém que coordene, que direcione e que execute,numa dinâmica muito bem articulada, e as intenções sejam convergentes a um ponto: os objetivos a serem conquistados.

Terá à frente dessa jornada de mudanças: a direção da escola conjuntamente com o corpo docente, o corpo discente e auxiliares da educação ( Secretaria ) para que sejam implantadas as mudanças de procedimentos, objetivando a efetivação de matrículas e a permanência dos alunos na escola afastando-os do fantasma da evasão escolar. 


\section{Cronograma de cumprimento do projeto:}

Conforme mencionado anteriormente, a realização da aplicação do projeto se dará no curso do segundo semestre de 2010, nas turmas da EJA, que iniciarão os seus estudos nesse semestre. Durante esse período haverá a implantação das mudanças de procedimentos na conduta dos trabalhos político-pedagógicos a serem desenvolvidos, visando o estancamento da evasão escolar. Possibilitando maior número de alunos possível a permanecer estudando, realizando as suas atividades com mais gosto e entusiasmo e sedimentando nos seus propósitos de iniciar e concluir os seus estudos.

No ato das matrículas, os candidatos deverão ser submetidos a uma triagem de confirmação de suas habilidades e competências adquiridas em etapas de estudos anteriores e que os habilitem ao prosseguimento dos estudos com eficiência na compreensão e absorção dos conhecimentos subseqüentes.

Serão oferecidos aos candidatos,meios pedagógicos e ambientais para que os mesmos sintam na escola um espaço de convivência social de troca de informações e construção de conhecimentos. 


\section{8- Possíveis Parceiros:}

As parcerias serão acordadas dentro da própria instituição, no nosso caso, O Centro Educacional 04 de Sobradinho II, que funcionará como o centro, onde serão desencadeadas as ações no cumprimento das tarefas advindas da dinâmica que o projeto exige.

Assim, será responsável pela aplicação do Projeto, contando com todos que atuam na funcionalidade do Estabelecimento, que tem como suporte, o apoio administrativo, incluindo alunos, professores, direção, orientação educacional, supervisores e servidores, como respaldo e parceria gerenciadora e orientadora das ações educacionais em cada área de abrangência.

Então, neste sentido, a escola contará com recursos próprios e caso, no decorrer da execução do projeto, poderá contar com parceiros empresariais, com recursos extra escolar, como parceria com gráficas para confecção de cartazes, folhetos, banners, malharia para confecção de camisetas, no intuito de promoverem uma campanha na própria escola, para minimização da evasão escolar na EJA.

\section{9- Orçamento:}

A implantação desse projeto conta com o orçamento programado para escola, pois as mudanças a serem feitas no processo educativo, não implicam em aumento de custos. Implica, sim, em mudanças nos procedimentos político-pedagógicos, em estratégias e articulações visando o objetivo fim,que é minimizar a evasão escolar. Não há necessidade de aumento de despesas para a implantação das mudanças preconizadas no projeto. 


\section{0- Acompanhamento e Avaliação:}

A avaliação da eficiência do projeto será processual, à medida que forem aplicadas as mudanças nos procedimentos, técnicas e estratégias pedagógicas e didáticas, não de forma modista, mas obedecendo critérios pré-estabelecidos para alcançar os resultados propostos pelo projeto: diminuição da evasão escolar na EJA.

No decorrer da primeira metade do semestre, levantar a realidade que se deseja mudar e de forma criteriosa, apurar o que já se conseguiu em termos de amenização do problema diagnosticado, comparando os números de evadidos, com outros períodos anteriores.

No pré-projeto, discutiu-se que todo o processo de avaliação será ao longo das medidas estabelecidas, previamente, e no tocante à realização das práticas das mudanças implementadas no decorrer do semestre de trabalho, à medida em que se obtiver efeitos positivos dentro dos objetivos pretendidos, como no caso dos objetivos específicos, poderemos distinguir, avaliar e medir a extensão das melhorias prováveis e esperadas. Quando falamos a palavra medir, não estamos referindo-se propriamente à avaliação, mas aos resultados, verificando se surtiu os efeitos desejados e esperados nas proporções em que se pretendia alcançar.

As ações avaliativas poderão ser trabalhadas em cada turma, segmento ou classe

numa freqüência regular. Toma-se por parâmetro avaliativo as realidades passadas e podemos concluir o grau de benefícios na solução do problema do diagnóstico. Será utilizada também, a auto avaliação realizada pelo próprio aluno. 


\section{1-Referências Bibliográficas.}

Alfabetização e cidadania: Revista de Educação de Jovens e Adultos. Brasília: RAAAB, UNESCO, Governo Japonês, 2006.

BRASIL. Constituição. Constituição da República Federativa do Brasil. Brasília: Senado Federal, 1988.

BRASIL. Parecer CNE/CEB 11/2000. Institui as Diretrizes Curriculares Nacionais da Educação de Jovens e Adultos, Brasília, 2000.

FREIRE, Paulo. Educação como prática da liberdade. Rio de Janeiro: Editora Paz e Terra,1996.

FREIRE, Paulo. Pedagogia da Autonomia - Saberes necessários à prática educativa. São Paulo: Editora Paz e Terra,1996.

FERREIRA, Aurélio Buarque de Holanda. Dicionário da Língua Portuguesa. 10ำ Edição, São Paulo, 1980.

. Ministério da Educação. Lei de Diretrizes e Bases da Educação Nacional. Brasília: MEC, 1996.

MORIN, Edgar. Os sete saberes necessários à educação do futuro- 2. ed. - São Paulo: Brasília, DF . UNESCO, 2000.

Pesquisa Nacional por Amostra em Domicílios (PNAD). Dados sobre Evasão Escolar e Analfabetismo, IBGE,Brasília, 2007. 
Universidade de Brasília/ Faculdade de Educação/ Curso de Especialização em Educação na Diversidade e Cidadania com Ênfase na EJA. Normas gráficas para formatação do PIL (Projeto de Intervenção Local).Brasília, UnB/FE, 2010. 